\section{Gestión de la movilidad humana en tiempos del COVID-19. Breve análisis}

\author{
Moisés Gómez y Fátima Peña ${ }^{1}$
}

Palabra clave:

movilidad humana, COVID-19, políticas migratorias de los EE. UU., solicitantes de asilo.

\section{Resumen}

Entre 2017 y 2020, la administración del presidente estadounidense Donald Trump ha implementado políticas de inmigración que han causado un daño enorme a miles de personas migrantes. Estas políticas migratorias han significado un desprecio y una violación de manera flagrante tanto a la legislación estadounidense como al derecho internacional y parecen haber tenido por objeto desmantelar el sistema de asilo de los EE. UU. Sin embargo, a partir de la pandemia del COVID19, estas medidas no se han detenido. Por el contrario, EE. UU. han tomado como excusa la crisis del COVID-19 para obstaculizar aún más el acceso al asilo, ha agilizado las deportaciones sin tomar en cuenta las condiciones de los países centroamericanos y ni el estado de salud de los deportados. Por su parte, el Gobierno salvadoreño ha carecido de un enfoque de derechos humanos para gestionar el retorno de las personas deportadas y de los ciudadanos varados en el extranjero.

\section{Introducción}

Se estima que 2.3 millones de salvadoreños residían en los EE. UU. en 2017, según un análisis del Centro de Investigación Pew de la Encuesta de la Comunidad Estadounidense de la Oficina del Censo de los EE. UU. (Noe-Bustamante et al., 16 de septiembre de 2019). La información anterior es del conocimiento del Gobierno salvadoreño, que también afirma que aproximadamente un tercio de la población salvadoreña vive fuera del país y, de esta, el $93.5 \%$ reside en los EE. UU., constituyéndose en la

1 Vicerrectoría de Proyección Social de la Universidad Centroamericana "José Simeón Cañas". 
segunda población más grande en ese país solo superada por población mexicana- en relación con la población inmigrante proveniente de América Latina y el Caribe, y la sexta en relación con la población inmigrante proveniente de todo el mundo (Ministerio de Relaciones Exteriores, 2018).

En 2001, El Salvador sufrió dos terremotos que dejaron cuantiosas pérdidas en vidas humanas y un daño muy grande en escuelas, hospitales, fábricas, empresas y cultivos echados a perder. Por esta razón, los EE. UU. concedieron a los salvadoreños elegibles el Estatus de Protección Temporal (TPS, por sus siglas en inglés), el cual otorga permisos de trabajo y protección temporal de deportación a ciudadanos de ciertos países que ya vivían en EE. UU. Actualmente, 195,000 salvadoreños gozan de ese estatus. A principios de 2018, la administración del presidente Trump anunció que no renovaría el TPS para los salvadoreños. Sin embargo, dichas acciones fueron desafiadas por la justicia federal y, al momento en que este texto era escrito, el TPS todavía estaba activo para los salvadoreños (O'Connor et al., 15 de agosto de 2019).

La migración salvadoreña transita mayoritariamente hacia los EE. UU. de manera irregular y a través de territorio mexicano, lo que significa una travesía colmada de peligros y de hechos violatorios de los derechos humanos y civiles (Ministerio de Relaciones Exteriores, 2018). Desde la crisis de niños, niñas y adolescentes no acompañados o en compañía de un familiar que llegaban a la frontera suroeste en el año 2014, ha habido un aumento significativo en la llegada de ambos flujos.

Durante el año fiscal 2018, la Patrulla Fronteriza (CBP, por sus siglas en inglés) arrestó a más de 38,000 niños no acompañados y casi a 104,000 individuos provenientes de El Salvador, Guatemala y Honduras que viajaban como parte de una familia en la frontera de México y los EE. UU. En ese mismo año, $58 \%$ de los menores no acompañados y $49 \%$ de aquellos inmigrantes que formaban parte de una familia proveniente del Triángulo Norte eran guatemaltecos. Hasta junio de 2019, la CBP había arrestado a más de 363,000 inmigrantes de familias provenientes de los tres países durante los primeros nueve meses del año fiscal, cifra que triplicaba el total de arrestos del año fiscal 2018. Un importante número de familias y niños no acompañados han solicitado asilo y muchos de ellos han sido puestos en libertad en los EE. UU. después de un proceso de audiencia en la corte migratoria de dicho país (Cf. U.S. Immigration and Customs Enforcement, 9 de agosto de 2020).

A finales de 2018, surge la modalidad de migrar en caravanas que presentan al menos tres características fundamentales: 1) se realizan vía terrestre, 2) se realizan en grupos numerosos y 3) hacen pública su huida, se autoconvocan y organizan desde las redes sociales como Facebook y Twitter. Las caravanas de migrantes en el norte de Centroamérica han ido desarrollándose a lo largo de los años (Gómez, 2020), pero han cobrado mayor relevancia tanto por número como por frecuencia a partir de octubre de 2018. La primera caravana salió el 13 de octubre desde San Pedro Sula, en Honduras, $y$ en el camino se unieron caravanas organizadas en San Salvador y Guatemala. Se estimó que al final de octubre habían ingresado a México entre 11,500 a 12,000 personas (EFE, 2 de noviembre de 2018), integrantes de las caravanas. En noviembre de 2018, llegaron a la frontera en el norte de México unos 6000 migrantes de la primera caravana; ahí quedaron con el sueño truncado junto a las playas de Tijuana.

\section{Objetivo}

El objetivo principal de este escrito es comprender el tratamiento político gubernamental de tres grupos de los grupos de población migrante más vulnerables: los solicitantes de asilo en la frontera de México y los EE. UU. (incluyendo centros de detención en los EE. UU.); los detenidos en estaciones migratorias en México, y los deportados desde México y los EE. UU. hacia El Salvador en el marco 
de la implementación de medidas para disminuir impacto de la pandemia del COVID-19.

\section{Metodología}

Este informe se elaboró utilizando un modelo mixto de técnicas cuantitativas y cualitativas con el fin de obtener una visión panorámica de cómo los gobiernos han gestionado la crisis causada por la pandemia del COVID-19 y su impacto en la población migrante en tres países: los EE. UU., México y El Salvador. Estos países son parte del ciclo migratorio de los salvadoreños. Para la recolección de información, se recurrió a fuentes primarias y secundarias.

En el caso de las fuentes primarias, se realizaron 19 entrevistas semiestructuradas con 15 preguntas organizadas en cinco apartados: 1) breve contexto de país en sus diferentes aspectos, 2) caracterización o perfiles de los flujos de migrantes, 3) medidas implementadas por los diferentes gobiernos ante el COVID-19 y cómo dichas medidas afectaron a los flujos migratorios, 4) acciones de respuesta por parte del Estado y la sociedad civil para atender a dichas poblaciones vulnerables, 5) recomendaciones de políticas, programas o proyectos de atención a esos flujos migratorios.

La distribución de los expertos entrevistados por país y sector al que pertenecen se muestra en la siguiente la Tabla 1. A todos los entrevistados, se les pidió su consentimiento informado para participar en la investigación; el acuerdo fue verbal. Además, se logró recoger el testimonio de dos jóvenes que regresaron deportados de los EE. UU. hacia El Salvador. Ambos fueron enviados a cuarentena por más de 30 días.

Tabla 1. Entrevistas realizadas por país y área de trabajo al que pertenecen

\begin{tabular}{|l|c|c|c|c|c|c|}
\hline \multicolumn{1}{|c|}{ País } & \multicolumn{9}{|c|}{ Área } & Total \\
\hline & $\begin{array}{c}\text { Defensoría } \\
\text { DDHH }\end{array}$ & Iglesia/Cáritas & Academia & $\begin{array}{c}\text { Casa de migrante/ } \\
\text { albergue }\end{array}$ & Deportados \\
\hline El Salvador & 4 & 2 & 2 & 1 & 2 & 11 \\
\hline México & 3 & 1 & 1 & 1 & 3 \\
\hline EE. UU. & & 1 & & 1 & 2 & 19 \\
\hline
\end{tabular}

Fuente: Elaboración propia.

Para la recolección de información a partir de fuentes secundarias, se seleccionaron, consultaron y analizaron diversas investigaciones, informes, artículos, comunicados, resoluciones, entre otros, de instituciones especializadas en el tema de migración y en temas de derechos humanos, a nivel local e internacional.

La revisión y análisis documental se vio enriquecida con algunos elementos propios de los estudios cualitativos, tales como las entrevistas semiestructuradas que permitieron obtener profundidad en cuanto al contexto de cada país, así como las experiencias de tratamiento a migrantes en detención, solicitantes de asilo y deportados.

Durante la redacción del informe, se realizó un análisis crítico de los principales hallazgos de las fuentes primarias y secundarias que se habían organizado previamente de acuerdo a ejes de análisis tales como acceso a salud, respeto a las garantías jurídicas (acceso al debido proceso, derecho al asilo y no devolución, derecho a no discriminación, entre otros) y, por último, las condiciones materiales en los centros de detención y contención. 


\section{Antecedentes}

El presidente de los EE. UU., Donald Trump, ha tenido la capacidad de alinear a México y Centroamérica hacia su política de contención migratoria. El muro de Trump es físico, legal, racista y xenófobo. Dicho muro ahora se ha fortalecido por el cerco sanitario que se ha impuesto por la pandemia del COVID-19. Por otro lado, la externalización de la frontera sur de los EE. UU. a territorio mexicano ha tenido graves consecuencias en el fenómeno migratorio de la región. Bajo un enfoque de seguridad y militarización, el control fronterizo se ha justificado como medio para detener el terrorismo, el tráfico ilegal de personas, drogas y el crimen organizado, lo que ha convertido a México en la frontera vertical de EE. UU.

El Programa de Atención Integral a la Frontera Sur (PFS) implementado a partir de julio de 2014, con el apoyo económico, técnico y político del Gobierno de los EE. UU., es parte del enfoque de externalización de fronteras basado en el discurso del miedo con el claro objetivo de convertir a México en el país que se encarga de detener y deportar a las personas migrantes y refugiadas que intentan llegar a EE. UU.

En México, Andrés Manuel López Obrador (AMLO), que al principio de su gestión se mostró condescendiente con la migración centroamericana y extracontinental y hablaba de que en su gobierno se les daría visas de trabajo a los migrantes y que no se les iba a deportar, cambió de parecer una vez que Trump le amenazó con imponer aranceles a los productos mexicanos que se venden en los EE. UU. AMLO les tiró la nueva Guardia Nacional a los flujos de migrantes. El plan era simple: detección, detención y deportación de los migrantes, y a los solicitantes de asilo los somete a estrategias de agotamiento físico y mental para que desistan de continuar el proceso.

La externalización de la frontera sur de EE. UU. se extendió hasta Centroamérica cuando Guatemala, Honduras y el Salvador firmaron los Acuerdos de Cooperación en 2019, que en la práctica los convirtió en "terceros países seguros", a pesar de ser una región con altas tasas de homicidios: en 2018 Guatemala terminó con 22.4, Honduras con 40 y El Salvador con 51 por cada 100,000 habitantes (Dalby y Carranza, 22 de enero de 2019).

\section{Contexto}

El 9 de enero de 2020, las autoridades de China identificaron un nuevo coronavirus causante de un brote de neumonía en la ciudad de Wuhan. Al 30 de enero, el virus se encontraba ya en todas las provincias de China continental y en otros países de cuatro continentes. En los EE. UU., se detectó el primer caso el 21 de enero. El 14 de febrero se detectó en Egipto el primer caso del COVID-19 en un extranjero. En El Salvador, el 22 de enero, en conferencia de prensa, el gabinete ampliado de salud anunció que, por órdenes del presidente Nayib Bukele, se tomaron medidas (cierre de fronteras para algunas nacionalidades; distanciamiento social; envío a casa a trabajadores mayores de 60 años y a aquellos con enfermedades crónicas; acceso en lugares de trabajo con antibacteriales; hasta llegar a la cuarentena domiciliaria y restricciones a la movilidad, entre otras) basadas en el Reglamento Sanitario Internacional de la Organización Mundial de la Salud (OMS) y se manifestó que el país estaba preparado para responder ante una Emergencia de Salud Pública de Importancia Internacional (ESPII) (Ministerio de Salud, 22 de enero de 2020).

El 11 de marzo de 2020, la OMS, por medio del director general, Adhanom Ghebreyesus, declaró que "el número de casos de COVID-19 fuera de China se había multiplicado por 13, y el número de países afectados se había triplicado" (OMS, 2020), por lo que el COVID-19 se consideraba ya una pandemia. El 11 de marzo 2020, los EE. UU. contabilizaban 1025 casos y 28 muertos, México contaba con 7 casos y en El Salvador no fue hasta el 18 de marzo que se identificó el primer caso del COVID-19. Desde el 11 de 
marzo, El Salvador había dispuesto que toda persona que llegara al país desde el extranjero cumpliera una cuarentena de 30 días en centros de contención (CC).

El 17 de marzo, se prohibió el ingreso de ciudadanos extranjeros y únicamente se permitió el ingreso de salvadoreños. Sin embargo, a partir del 21 de marzo, el Gobierno de El Salvador comenzó a tomar las medidas más drásticas para evitar la propagación del COVID-19: el presidente Nayib Bukele, en cadena nacional, anunció una cuarentena general obligatoria de 30 días, acompañada de un régimen de excepción que había sido aprobado el 14 de marzo y que tuvo vigencia hasta el 14 de abril. Pese a ello, la cuarentena obligatoria se mantuvo hasta el 22 de mayo. A la fecha de cierre de este informe (julio), el país está en la fase 1 de contención del virus; legalmente no hay ningún decreto ejecutivo o legislativo que deba cumplir la población. Sin embargo, el país está guardando cuarentena domiciliar y la economía camina a medio andar.

Tabla 2. Número de casos del COVID-19 en El Salvador (hasta el 7 de julio 2020)

\begin{tabular}{|c|c|c|c|}
\hline Casos confirmados & Casos recuperados & Casos fallecidos & Casos activos \\
\hline 8307 & 4929 & 229 & 3149 \\
\hline
\end{tabular}

Fuente: Gobierno de El Salvador (2020). https://COVID19.gob.sv

En términos políticos, el país recibió esta pandemia en un período de gobierno que algunos analistas consideran que estará marcado por la "tentación autoritaria" (ArtigaGonzález, 2020). Al observar las acciones del presidente Nayib Bukele, se puede confirmar esta advertencia. A casi un año de su gestión, el autoritarismo está más evidenciado, por ejemplo, cuando en febrero de 2020 Bukele llevó soldados al Congreso para intimidar a los legisladores con el fin de que aprobaran un proyecto de ley. Al mes siguiente, Bukele no acató una resolución de la Corte Suprema de Justicia para que dejara de usar al ejército en los operativos de detención de los infractores de la cuarentena. Más tarde, abogó por el uso de la fuerza letal en una ofensiva contra las pandillas criminales que, según el gobierno, tuvieron participación en el alza de homicidios del país a finales del mes de abril.

Como base de esa tentación autoritaria, estaría una realidad: grandes problemas sociales, descrédito del sistema de partidos y de la institucionalidad del Estado, altos índices de violencia y de desigualdad, entre otros, que han generado un gran descontento en la población salvadoreña y que fueron determinantes para el triunfo de Bukele en febrero de
2019. Bukele prometió resolver esos grandes problemas que afectan a la población, pero en el ejercicio de su gobierno se han dado muestras de una forma autoritaria de ejercer el poder que desconoce y descalifica el Estado de derecho, la Constitución de la República, a los partidos de oposición y a todo actor de la sociedad civil que se interponga entre el presidente y "su pueblo".

En la práctica y según la narrativa oficial, los opositores son todos aquellos que no quieren que se resuelvan los problemas sociales (salud, educación, empleo, salarios, seguridad, etc.) (Departamento de Sociología y Ciencias Políticas de la UCA, 2019). En este sentido, la pandemia del COVID-19 está siendo utilizada por el presidente Bukele para "barrer" y deslegitimar esos obstáculos. Él es la nueva "norma", la "ley", su intención es ser juez: juzga, establece lo correcto y lo incorrecto para el pueblo y para el país, su gabinete solo cumple órdenes. Tiene control de las Fuerzas Armadas (FAES) y de la Policía Nacional Civil (PNC). Los funcionarios tienen poco criterio y poca capacidad de decisión y acción en el ámbito que les compete. Todo esto ha llevado al país a una triple crisis: sanitaria, económica y democrática. 


\section{El COVID-19 como excusa para negar protección internacional}

Un campo de concentración es una zona donde el Estado de derecho no se aplica.

La congresista demócrata de los EE. UU. Alexandria Ocasio-Cortez, al visitar la frontera sur, tuiteó a mediados de junio de 2019: "Esta administración ha establecido campos de concentración en la frontera sur de los EE. UU. para migrantes, donde están siendo brutalizados con condiciones deshumanizantes y muriendo" (Lissardy, 2019). En el entorno político y mediático, se desató un fuerte debate en el que se tomó como base el hecho de que existen 200 lugares en EE. UU. donde el Servicio de Inmigración y Control de Aduanas de los EE. UU. (ICE, por sus siglas en inglés) tiene detenidas diariamente a más de 50,000 personas, en su mayoría inmigrantes sin papeles, refugiados y solicitantes de asilo latinoamericanos. Hasta el 25 de abril 2020, la ICE reportaba 26,675 personas detenidas en sus centros. La polémica y el debate de llamar campos de concentración a los centros de detención para migrantes fue respaldada por Erika Guevara-Rosas, directora para las Américas de la organización defensora de derechos humanos Amnistía Internacional: "Si se trata de hacer una reflexión de lo que estos centros de detención de personas migrantes hoy día constituyen en los EE. UU., no habría dudas en llamarlos campos de concentración" (Lissardy, 2019)

Las políticas migratorias restrictivas de $\mathrm{EE}$. UU. que dificultan la entrada de latinos no son nuevas, tal como argumentan Massey \& Pren (2013):

Durante los años 1970 y 1980 los inmigrantes latinos se transformaron en un grupo simbólico y convenientemente utilizado para aumentar el pánico moral de aquellos cuya fuerza política podría ser utilizada para acumular poder y asegurarse recursos administrativos (Chávez 2001; Massey 2007; Flores et al., 2011). La construcción de los inmigrantes latinos como amenaza originó el despertar de un electorado y la puesta en marcha de leyes restrictivas a la inmigración y políticas más duras en la frontera, que aumentaron el número de detenciones de inmigrantes, justificaron nuevas restricciones y acciones en la aplicación de la ley migratoria. Estas restricciones dieron pie a más detenciones, que justificaron la necesidad de acciones más rigurosas e impositivas y produjeron un ciclo de retroalimentación que impulsó los esfuerzos por aplicar la ley.

Al seguir el desarrollo histórico de las detenciones de migrantes $\mathrm{y}$, sobre todo, del discurso de "la necesidad de acciones más rigurosas e impositivas", no es casualidad notar que, en su primera semana como mandatario, Trump firmó la orden ejecutiva que autorizaba la construcción de un muro en la frontera sur del país (Redacción BBC News Mundo, 2 de noviembre de 2016). Adicionalmente, en 2019, Trump firmó acuerdos de "cooperación" en materia migratoria con países latinoamericanos, entre ellos, México (enero), Guatemala (26 de julio), Honduras (20 de septiembre) y El Salvador (25 de septiembre). Estos acuerdos constituyen, en la práctica, una especie de muro "legal" que bloquea el acceso a la protección internacional y traslada el muro físico fronterizo entre México y los EE. UU. hasta cada una de las fronteras de los países del norte de Centroamérica. En 2018, se reveló que Guatemala, Honduras y El Salvador ocuparon el segundo, el tercero y el cuarto lugar, respectivamente, como países de origen de las personas que más pedían asilo en los EE. UU., según la memoria de labores del Departamento de Justicia de 2018 (Alvarado, 26 de septiembre de 2019).

Seguramente, este dato fue el detonante para que la administración de Trump forzara a los países del norte de Centroamérica a que firmaran los Acuerdos de Cooperación en materia de Asilo (conocidos como ACA). Para esas fechas, Geoff Thale, vicepresidente de programas en la Oficina en Washington para Asuntos Latinoamericanos (WOLA), dijo que "la administración Trump está tratando de 
convertir a Centroamérica misma en un muro. Es inmoral e inhumano atrapar a quienes buscan asilo en una región no equipada para procesar sus reclamos de forma justa, mantenerlos seguros, o garantizarles condiciones de vida decentes" (Thale, citado en Rauda Zablah, 20 de septiembre de 2019).

En ese contexto, el 30 de mayo de 2019, Trump amenazó con imponer aranceles -inicialmente del $5 \%$ - a "todos los bienes importados" desde México y, si se toma en cuenta que siete de cada diez productos que fabrica México tienen como destino los EE. UU., de cumplirse la amenaza de Trump, la economía mexicana podría haberse visto fuertemente impactada. Trump mantendría la amenaza "hasta que se detenga el flujo de migrantes indocumentados" que llega a los EE. UU. a través de ese país.

La presión funcionó y México dispuso que la Guardia Nacional resguardara la frontera sur y literalmente bloqueara cualquier intento de los migrantes por cruzar México. Además, el Gobierno mexicano hizo que el Instituto Nacional de Migración mexicano (INM) radicalizara el mecanismo de detección, detención y deportación de migrantes y, simultáneamente, que recibiera a los centroamericanos y migrantes de otras nacionalidades solicitantes de asilo en los EE. UU. para que esperaran todo el proceso de solicitud de asilo en territorio de México mientras llegara la fecha de presentarse ante la Corte de Inmigración estadounidense. La medida se llama oficialmente Protocolo de Protección de Migrantes (MPP, por sus siglas en inglés), pero se conoce mejor por el sobrenombre de "Quédate en México". Su objetivo es desincentivar la idea de que basta con llegar a la frontera para entrar en territorio de los EE. UU. y quedarse. Estos protocolos requieren que ciertos ciudadanos de otros países que ingresen ilegalmente o soliciten la admisión a los EE. UU. desde México sin la documentación adecuada sean "devueltos a México y esperen fuera de los EE. UU. por la duración de sus procedimientos de inmigración" (TRAC Immigration, 2020).
Aunque el acuerdo MPP se anunció en enero de 2019, lo cierto es que se implementó desde diciembre de 2018, actualmente alrededor de 59,000 personas han quedado detenidas en el lado mexicano de la frontera esperando una cita con el juez en EE. UU. para exponer su petición de asilo. El COVID-19 ha trastocado todo el sistema de fechas de corte y actualmente todas las audiencias de MPP están pospuestas hasta nuevo aviso. Aquellos solicitantes que tenían audiencias entre el 10 de mayo y el 8 de junio no se presentarán al puerto de entrada asignado; si la audiencia la tenían antes del 22 de junio, deberán presentarse en el puerto de entrada un mes después de la fecha indicada.

Estos cambios en el papel se hacen rápido, pero para las personas atrapadas en las ciudades fronterizas es un calvario adicional porque no tienen los recursos, ni ellos ni las ciudades que los albergan. Nunca nadie les preguntó o les dio apoyo para atender ese flujo compuesto por familias enteras, con hijos e hijas, con enfermedades crónicas, con necesidades especiales de atención. Un informe que recoge las conclusiones de un viaje que la directora de Incidencia y Operaciones del Servicio Jesuita a Refugiados de los EE. UU. (JRS USA) realizó al sur de México justo antes del cierre que resultó de la pandemia relata que un abogado de una organización de apoyo a solicitantes de asilo en Ciudad Juárez y El Paso (Texas) narró la historia de una migrante bajo el MPP que murió porque no pudo acceder a atención médica en el albergue en el que estaba esperando la cita de la Corte de Inmigración. Aun después de fallecida, el abogado siguió con el apoyo para repatriarla a su comunidad de origen. Los solicitantes de asilo permanecen en un estado de limbo perpetuo, que puede continuar incluso después de la muerte.

En el contexto del COVID-19, Trump no dudó en utilizar la pandemia como otra excusa para sellar el acceso a inmigrantes solicitantes de asilo; tanto así que, desde el 21 de marzo, la Oficina de Aduanas y Protección Fronteriza de los Estados Unidos (CBP, por 
sus siglas en inglés), usando el mecanismo fast track o exprés, deporta en menos de dos horas a los migrantes indocumentados. Tan solo en el periodo del 21 de marzo al 10 de abril, la administración de Donald Trump deportó de manera exprés a casi 10,000 migrantes. La CBP argumentó que las deportaciones responden a una ley de salud pública que permite deportar, en menos de dos horas, a los migrantes y negar la entrada a los extranjeros que pudieran representar un "riesgo" de transmitir enfermedades infecciosas. Sobre este aspecto, una actualización gráfica (Tabla 3):

Tabla 3. Estadísticas de detenidos de ICE relativas al COVID-19, por instalación

\begin{tabular}{|c|c|c|}
\hline $\begin{array}{l}\text { Población detenida (al 4 de } \\
\text { julio de 2020) }\end{array}$ & $\begin{array}{l}\text { Casos positivos del COVID-19 bajo } \\
\text { custodia actualmente (bajo aislamiento o o } \\
\text { monitoreo al 8 de julio de 2020) }\end{array}$ & $\begin{array}{l}\text { Detenidos examinados (al } \\
\text { 3 de julio de 2020) }\end{array}$ \\
\hline 22,579 & 871 & 11,828 \\
\hline
\end{tabular}

Fuente: Guía de ICE sobre el COVID-19 (2020). https:/www.ice.gov/es/coronavirus

La Cancillería salvadoreña declaró que al menos un salvadoreño murió por COVID-19. La víctima, de 57 años, se contagió estando bajo custodia del ICE y falleció el miércoles 6 de mayo en el Centro de Detención Otay Mesa, en San Diego (Ministerio de Relaciones Exteriores, 7 de mayo de 2020).

El tema de la detención es un asunto de interés de la administración Trump. Se trata de un negocio millonario y del que Trump se ha beneficiado con donaciones para su campaña política. La máquina de detención es una piñata, quien la controla posee la llave de la abundancia que da como resultado miles de millones de dólares en ingresos para operadores privados que no dudan en apoyar a candidatos que vean en la detención de migrantes, solicitantes de asilo y refugio la oportunidad de negocios millonarios. Las críticas sobre la gestión privada de esos centros de detención no han parado. Por ejemplo, la Unión Estadounidense de Libertades Civiles (ACLU, por sus siglas en inglés), Human Rights Watch (HRW) y el Centro Nacional de Justicia para Inmigrantes (NIJC, por sus siglas en inglés) realizaron un estudio que incluyó una visita a cinco centros de detención ubicados en Luisiana, Misisipi y Arizona, más de 150 entrevistas a personas detenidas y la revisión de documentos solicitados al gobierno por medio de la ley de libertad de la información. Las organizaciones denunciaron que, desde el inicio de la presidencia de Trump en 2017, se han abierto 40 nuevos centros de detención. La mayoría están a cargo de operadores privados.

Desde enero de 2020, el $81 \%$ de las personas detenidas están en instalaciones que son propiedad de, o son operadas por, empresas privadas. Ese porcentaje sube al $91 \%$ para las personas detenidas en instalaciones que abrieron después de 2017 (por la administración Trump). Las personas permanecen recluidas en condiciones inhumanas y el acceso a la atención médica es insignificante, incluso antes de la pandemia. Desde 2017, 39 adultos han muerto bajo custodia del ICE o inmediatamente después de ser liberados. Doce de estas muertes fueron por suicidio mientras estaban detenidos. Dos de los cinco centros de detención que visitaron los investigadores no tenían un profesional de salud mental entre su personal, los detenidos no tienen acceso a un abogado. Respecto a los solicitantes de asilo, el estudio encontró que se ha experimentado un crecimiento sin precedentes y sin control en la detención de inmigrantes y solicitantes de asilo en la última década. "Bajo la administración Trump, ese crecimiento ha sido parte de un ataque total contra el debido proceso y las leyes de asilo que ha mantenido a las personas encerradas en centros de detención por períodos prolongados con pocas esperanzas de salir, incluso 
en el escenario de pesadilla del mundo global" (ACLU, 2020) Según esa investigación, los solicitantes de asilo ven prácticamente imposible su liberación. El ICE no parece interesado en reducir el hacinamiento en los centros de detención, a pesar de los riesgos a la salud que esto podría ocasionar.

Los centros de detención han sido catalogados como "zonas libres de justicia" (similares a un campo de concentración donde el Estado de derecho no aplica). Pese a lo descrito anteriormente, Trump planea pedir para el año fiscal 2021 que los contribuyentes financien al ICE en USD 4.1 mil millones, con la intención de ampliar la capacidad de detención diaria a 60,000 personas (ACLU, 2020).

En entrevista con el director ejecutivo de Alianza América, él afirma que el presidente Trump promovió ante el Congreso eliminar la barrera de las 34,000 atenciones diarias como máximo legal permitido. Ahora, sin esa barrera, busca tener 60,000 detenciones al día, razón por la que necesita aumentar el financiamiento del ICE en 2021. Adicionalmente, este director ejecutivo mencionó que las condiciones son aún más complejas para los migrantes y solicitantes de asilo, debido a la existencia de una campaña sistemática e incansable que viene desde los años setenta, que enfatiza que los inmigrantes son una amenaza para la forma de vida "americana". Hay una atmósfera antiinmigración que permea a todo el país y permite la discriminación racista hacia cualquier persona originaria de Asia, África, y principalmente latinoamericanos, independientemente de su condición migratoria. Según Alianza América, Trump ha aprovechado este ambiente hostil hacia los migrantes. En ese sentido, confluyen dos efectos que se unen en la figura de Trump: la creciente cultura racista y discriminatoria y el aumento de leyes y decretos contra la inmigración, que tiene como consecuencia más detenciones y más vulneración de derechos de los migrantes. Todas estas medidas tienen un alto costo para los contribuyentes estadounidenses (Chacón, 2020)

\section{Liberados para ser deportados. Arrojados a su suerte en México}

Para dimensionar el problema al que se enfrentan los migrantes y solicitantes de asilo, hay que tener en cuenta que en México existen 65 estaciones y albergues migratorios administrados por el Instituto Nacional de Migración (INM). La capacidad de ocupación es de 8,524 espacios. De forma regular, todas esas estaciones migratorias presentaban hacinamiento en los meses previos al aparecimiento del COVID-19. En junio de 2019, la Comisión Nacional de los Derechos Humanos (CNDH) detectó estaciones y estancias migratorias que sobrepasan su capacidad hasta en $300 \%$. Un funcionario de esa institución aseguró que las instalaciones que presentaban mayor sobrepoblación se encuentran en Tapachula, San Cristóbal, Huixtla y Huehuetán.

El 30 de marzo de 2020, en la estación migratoria de Tenosique, Tabasco, murió un solicitante de asilo originario de Guatemala, tras un incendio registrado cuando migrantes encerrados protestaban por sus condiciones de encierro. La 72. Hogar-Refugio para Personas Migrantes declaró que "ante el cierre de fronteras en los países de la región, como medida de contingencia por el COVID-19, el INM no escuchó el llamado de la CNDH, que exigía acciones urgentes para evitar hacinamiento y contagio masivo de coronavirus en personas migrantes, ni las recomendaciones de la sociedad civil para liberar a las personas detenidas, muchas solicitantes de refugio, o reubicarlas en Casas del Migrante del centro del país, evitando el confinamiento y reduciendo riesgo de contagio" (La 72. HogarRefugio para Personas Migrantes, 2020)

En abril de 2020, organizaciones de base y religiosas, con el apoyo de líderes religiosos de América Central, México y EE. UU. que trabajan para abordar las causas profundas que obligan a las personas a abandonar sus hogares en la región, publicaron una carta abierta dirigida al Gobierno de México. En dicha carta, se solicitaba con carácter urgente "la liberación inmediata de todas las personas 
migrantes, refugiadas y solicitantes de asilo, que se encuentran en centros de detención migratoria" (Al Otro Lado et al., 15 de abril de 2020).

La presión de organizaciones de sociedad civil en México, en EE. UU. y Centroamérica para que el INM liberara y priorizara la atención sanitaria de esa población, con el apoyo y coordinación con iniciativas de la sociedad civil que gestionan casas y albergues para migrantes en el centro de México, tuvo eco en el Gobierno mexicano. No obstante, la respuesta del INM fue opuesta a lo que exigía la comunidad organizada: deportó a 3653 migrantes del Triángulo Norte de Centroamérica (TN) por vía terrestre y aérea. Solo así se entiende el drástico descenso de personas detenidas que informó el INM en el Boletín N. ${ }^{\circ}$ 125/2020, que pasó de reportar 3759 migrantes detenidos en marzo a solo 106 hasta el 26 de abril (INM, 26 de abril de 2020).

Un alto funcionario del Gobierno mexicano declaró ante la Comisión de Asuntos Migratorios de la Cámara de Diputados que el Gobierno de México "evitó" el contagio de los migrantes detenidos al repatriar a 4303 personas, principalmente de Honduras, El Salvador y Guatemala desde el 21 de marzo a la fecha y redujo a solo 231 personas la población en sus estaciones migratorias (Damián, 12 de mayo de 2020).

La coordinación del Programa de Asuntos Migratorios de la Universidad Iberoamericana de la Ciudad de México (PRAMI) e integrante del colectivo que envió la carta abierta que pedía las autoridades la liberación de los migrantes detenidos, afirma que al Gobierno mexicano se le exigió la liberación inmediata de la población y que se gestionara un puente humanitario en donde hubiera alternativas dignas para las personas que salían de la estación migratoria bajo el precepto de que el Estado es responsable de que las personas estén en condiciones dignas. También, decía la informante, que pedían una liberación ordenada, según prioridades, y que no implicara deportaciones inmediatas, sino crear las condiciones necesarias fuera de la estación migratoria para que estas personas en libertad fuesen atendidas y auxiliadas. La entrevistada agregó que, al final, las autoridades mexicanas no garantizaron condiciones dignas para liberar a los migrantes:

Nos dieron atole con el dedo, como decimos acá, y lo que pasó fue que de un momento a otro nos enteramos de que habían vaciado las estaciones migratorias, que la manera de vaciar esas estaciones migratorias fue a través de la deportación de personas, a pesar de que les dijimos que la deportación no era la solución. Sabemos cómo están las condiciones en C. A. y lo otro que pasó es que al resto lo tiraron a la calle tal cual. Tuvimos casos como el de Oluta, en Veracruz, donde tuvieron que recibir a la gente si o si porque ya estaban ahí afuera del albergue. O sea, es una situación bien difícil porque a todas las personas que estaban en detención y que fueron tiradas a la calle, las fueron a dejar a las fronteras para que se busquen la vida para regresar de manera irregular a sus países (PRAMI, 2020).

Además, los albergues y las casas para migrantes tuvieron que cerrar desde marzo debido al COVID-19, por lo que ya no pudieron recibir más personas y solo se mantuvo en algunos de ellos a un pequeño grupo vulnerable que, por razones humanitarias y de salud, tenía que seguir recibiendo apoyo. Definitivamente, ningún albergue tiene condiciones para mantener población en resguardo debido a que no hay suficiente espacio para guardar el distanciamiento físico que la COVID-19 exige, no hay suficientes recursos para tener alcohol gel y otros productos sanitizantes. En su mayoría, tampoco cuentan con especialistas en salud.

Por otro lado, en la mayoría de las casas y albergues gestionados por actores de iglesia o personas altruistas, se han limitado a proveer una o dos comidas por día a los migrantes en situación de calle que llegan al local. También siguen orientando legalmente a los solicitantes de asilo, se mantiene el apoyo psicosocial y 
el acompañamiento espiritual. En entrevistas realizadas a dos responsables de albergues, ambos coincidieron en que la crisis por la pandemia los sorprendió sin formación $y$ sin conocimientos para atender con conocimientos técnicos la crisis por el COVID-19 y sus posibles impactos.

Ambos también manifiestan que, según la necesidad de atención a la población migrante, han aprendido y creado protocolos de protección para el personal del albergue y para ser implementados entre la población albergada y/o en las atenciones externas.

Cuando se detectan casos sospechosos de COVID-19, estos son remitidos a centros especializados y luego regresan al albergue, siempre y cuando las autoridades quieran brindar este servicio que por derecho tienen los migrantes. Sin embargo, en la mayoría de casos, las autoridades de los centros de salud les han dicho a los responsables de albergues que no envíen migrantes y que tampoco tienen capacidad de darles los insumos necesarios. El COVID-19 ha aparecido en algunos albergues, no en todos.

En cuanto a la pregunta por el apoyo recibido de parte de las autoridades locales, la respuesta es que en algunos albergues sí han recibido apoyo gubernamental, ya sea municipal, estatal o federal para gestionar la crisis del COVID-19, mientras que en otros casos los entrevistados manifestaron que no habían recibido ningún apoyo. Por el contrario, en algunas ocasiones, las autoridades han fomentado la aversión y la xenofobia hacia los albergues y, por ende, hacia los migrantes.

En relación con el acceso a la salud, en general, el personal de los albergues ha manifestado toda la disposición de reabrirlos progresivamente, aunque conscientes de que sus labores deberán adaptarse a las nuevas condiciones. Por otro lado, los entrevistados también mencionaron que, durante el trans- curso de la pandemia, han recibido menos migrantes en tránsito, solicitantes de asilo o migrantes con necesidades especiales (usualmente con lesiones por caídas del tren "la Bestia").

Además, los entrevistados coincidieron en que hay otros problemas a los que deben enfrentarse, por ejemplo, afirman que los migrantes no creen en el coronavirus y piensan que a ellos no les puede afectar. De la misma manera, los entrevistados también manifestaron que hay serios problemas entre los migrantes "varados" o "quedados", ya que algunos de ellos han perdido sus empleos debido a la pandemia y otros que deambulan buscando trabajo, pero que, al no encontrarlo, caen en situación de indigencia.

Los consulados de los países de origen de estas personas suelen ignorar esa realidad de sus connacionales. Los albergues no tienen la capacidad de hacerse cargo de esa población en indigencia. Esta situación genera conflictos y rechazo hacia los migrantes por parte de la población local. De ahí que, según los entrevistados, es importante fomentar una cultura de hospitalidad.

La burocracia torturadora: la estrategia del desgaste y el cansancio para los solicitantes de asilo en México

En México, la Comisión Mexicana de Ayuda a Refugiados (COMAR) reporta que de enero a junio de 2020 recibió en sus cuatro delegaciones (CDMX, Chiapas, Tabasco y Veracruz) 20,496 solicitudes de asilo. Las nacionalidades con mayor número de solicitantes fueron: Honduras con 6451, Haití con 3661, Cuba con 3068, Venezuela con 2014, El Salvador con 1866, y Guatemala con 1272 (COMAR, 2020). Al comparar las estadísticas de enero a junio de 2018, 2019 y 2020, se puede observar un descenso significativo de solicitudes de asilo en este período (ver Tabla 5). 
Tabla 4. Cantidad de personas solicitantes de asilo en México

\begin{tabular}{|l|l|}
\hline Enero a junio de 2018 & 29,630 \\
\hline Enero a junio de 2019 & 70,609 \\
\hline Enero a junio de 2020 & 20,496 \\
\hline
\end{tabular}

Fuente: elaboración propia con datos de estadísticas de COMAR 2020. https://clck.ru/PZiRp

Tabla 5. Solicitantes de la condición de refugiado en México (2020)

\begin{tabular}{|l|c|}
\hline \multicolumn{2}{|c|}{ Nacionalidades } \\
\hline Honduras & 6451 \\
\hline Haití & 3661 \\
\hline Cuba & 3068 \\
\hline Venezuela & 2014 \\
\hline El Salvador & 1866 \\
\hline Guatemala & 1272 \\
\hline \multicolumn{2}{|c|}{ Niños, niñas y adolescentes } \\
\hline Acompañados & 3955 \\
\hline No acompañados & 204 \\
\hline \multicolumn{2}{|c|}{ Por delegación } \\
\hline CDMX & 12767 \\
\hline Chiapas & 5210 \\
\hline Veracruz & 12,853 \\
\hline Tabasco & 1276 \\
\hline & \\
\hline & \\
\hline
\end{tabular}

Fuente: COMAR (2020). https://clck.ru/PZiRp

A partir de los datos anteriores, se podría inferir que ese descenso en las solicitudes de asilo podría atribuirse a la implementación de las medidas de prevención del COVID-19 y que no se permite a la población migrante el acceso a la protección internacional. Previendo esta crisis, la oficina del Alto Comisionado de las Naciones Unidas para los Refugiados (ACNUR), en el contexto del COVID-19, ha hecho un llamamiento muy importante a los Estados: solicita el cumplimiento al derecho de solicitar asilo y al principio de "no devolución" de las personas refugiadas. Además, ACNUR pide a los Estados que se les brinde a las personas solicitantes de asilo información en un idioma que puedan entender y solicita también que las medidas que se tomen para prevenir el COVID-19 no deben ser discriminatorias ni debe impedir 
la llegada de personas solicitantes de asilo (ACNUR, 2020).

Sin embargo, en este mismo contexto, la política migratoria en México es ambigua y posee una contradicción. Por un lado, las autoridades afirman en que se reconocen derechos a las personas migrantes, a víctimas de trata, a niños, niñas y adolescentes (NNA) y afirman que México es un país garante de los tratados y convenios internacionales firmados y ratificados (entre ellos la Convención Americana sobre Derechos Humanos) y que respeta los derechos humanos. Por otro lado, se incrementa la persecución, detección, detención y deportación de aquellas personas cuyos derechos se pretende proteger con las leyes promulgadas. Actualmente, México ya es un país tanto de tránsito como de destino (y también de origen para nacionales hacia los EE. UU. y de retorno de estos nacionales desde dicho país). Este ejercicio de fingir respeto de los derechos humanos se realiza con la intención de que un mayor número de personas migrantes y refugiadas se queden en México y así se retenga el mayor número de las que transitan hacia los EE. UU. Esta estrategia, que cuenta con financiación estadounidense, es una muestra más del patrón de externalización de fronteras que rige las políticas migratorias de muchos países con economías fuertes, tales como los EE. UU. (CEAR, 2018).

\section{Recepción de deportados en el país: la continuación de la tortura en los centros de contención}

La maquinaria de deportaciones está más viva que nunca. En cierto modo, la pandemia es la nueva ley de migración y es el nuevo pacto para una migración segura, ordenada y regular. De hecho, aunque en Centroamérica la mayoría de países tenga restricciones de ingreso a los países, esto no ha sido un impedimento para continuar con las deportaciones. Un ejemplo de la continuidad de las deportaciones lo reporta la Iniciativa Kino para la Frontera (KBI, por sus siglas en inglés), un proyecto binacional de los jesuitas de los EE.
UU. y México, ubicado en Nogales (Arizona) y Nogales (Sonora). En la actualización mensual del contexto de mayo, la dimensión de incidencia de la Red Jesuita con Migrantes Centro y Norteamérica menciona que:

Se ha bajado mucho el número de personas migrantes llegando a Nogales. Por ejemplo, en abril recibimos solo 151 nuevas personas cuando en un mes recibíamos un promedio de 700 nuevas personas. De los 151, 30 iban llegando para intentar el cruce o pedir asilo, 7 fueron regresados bajo MPP, 81 fueron deportados después de intentar cruzar la frontera y 33 fueron detenidos viviendo en EEUU y deportados desde allá (sic).

Acaban de anunciar que empezarán vuelos de deportación de San Diego, California, a la Ciudad de México (habían suspendido deportaciones vía aérea de EU a México durante la pandemia, pero ahora los están reiniciando).

Los contagios dentro de los centros de detención se han expandido y todavía ICE no está aplicando muchas pruebas, así que es muy probable que el número real sobrepase las estadísticas. Hasta ahora ha habido 1073 casos confirmados en los centros de detención y solo han aplicado la prueba a 2172 personas. Nos escribió una persona que está en detención en La Palma: "Le cuento que las cosas acá están empeorando, es oficial la presencia del virus en este lugar y lo peor es que actúan como si nadie estuviera pasando demeritando la gravedad del asunto, diciendo cosas como que eso no se contagia tan fácilmente, que no mata, que es un simple flu, etc., pero cada día hay más personas en cuarentena en unidades aisladas incluyendo la mía donde el día de ayer se llevaron a un detenido que aparentemente está infectado" (Williams, 19 de mayo de 2020).

Entonces surge la pregunta: ¿por qué siguen las deportaciones desde México y los EE. UU. hacia el país si desde el 11 de marzo 
El Salvador decretó una cuarentena en todo el territorio nacional que establecía que todos los salvadoreños que ingresaran al país debían cumplir aislamiento en centros de contención? Además, si el 17 del mismo mes se cerró finalmente su aeropuerto y sus fronteras, ¿cómo es que las deportaciones nunca dejaron de llegar y de recibirse? Ante estas medidas, la lógica indicaba que las deportaciones iban a detenerse mientras los países del Triángulo Norte lidiaban con la crisis del COVID-19. Sin embargo, ni el ICE ni el INM detuvieron sus vuelos ni sus autobuses con personas deportadas hacia Centroamérica.

Esto se explica, primero, porque los EE. UU. necesitan disminuir el hacinamiento en los centros de detención; segundo, porque, en México, la deportación ha sido la regla hacia los indocumentados como prueba, ante Trump, de su colaboración para frenar la migración hacia el norte.

Adicionalmente, las deportaciones continúan porque tanto Guatemala, como Honduras y El Salvador tienen acuerdos previos que son aparentemente inviolables, inexorables y no pueden dejar de ejecutarse. Cuando aparece la pandemia, la excusa para las deportaciones es la salud de los migrantes: se les deporta como una forma de prevenir el virus.

Tal como se ha documentado, existe suficiente evidencia del riesgo de contagio al que los migrantes han sido expuestos en los centros de detención en los EE. UU. (ACLU, 30 de abril de 2020; TRAC Immigration, 2020), así como en las estaciones migratorias en México (La 72. Hogar-Refugio para
Personas Migrantes, 2020; PRAMI, 6 de mayo de 2020). Asimismo, la prensa independiente ha realizado reportajes de investigación que explican que el proceso de deportación ha sido una tortura que va desde largas jornadas de viaje sin parar (Pradilla, 12 de abril de 2020) hasta dejarlos abandonados a su suerte a medio camino (Menchú y Mariscal, 2020).

Aparte de enfrentarse a ese extenuante viaje para llegar a Guatemala, las personas deportadas también se enfrentan al riesgo de ser amenazadas con ser quemadas si tratan de entrar a Guatemala. Las periodistas Ángeles Mariscal y Sofía Menchú narran la historia de Carlos Cume, migrante guatemalteco que regresó deportado $y$, a pesar de que las pruebas del COVID-19 que le hicieron en el centro de detención de los EE. UU. salieron negativas y que ese diagnóstico lo certificó el Ministerio de Salud de Guatemala, la comunidad se organizó para impedir que él entrara a Santa Catarina Palopó en el altiplano guatemalteco: "Él venía ya con sus papeles, pero las personas no se quedaron conformes, nos dijeron que nos iban a linchar igual a mi hermano y a toda la familia", cuenta su hermano Juan Cumes (Menchú y Mariscal, 2020)

En El Salvador, se han reportado casos de personas deportadas que han sido vilipendiadas por agentes de la Unidad de Mantenimiento del Orden (UMO) de la Policía Nacional Civil (PNC) mientras cumplen su cuarentena en centros de contención.

En el Triángulo Norte, los datos disponibles sobre la cantidad de deportados de enero a mayo de 2020 son los siguientes:

Tabla 6. Retornos al Triángulo Norte de Centroamérica (enero-mayo de 2020)

\begin{tabular}{|l|c|c|c|}
\hline \multicolumn{1}{|c|}{ País } & Enero-mayo 2019 & Enero-mayo 2020 & Variación \\
\hline El Salvador & 13,288 & 7072 & $-6216(-46.8 \%)$ \\
\hline Guatemala & 43,532 & 23,516 & $-20,016(-46.0 \%)$ \\
\hline Honduras & 44,278 & 21,861 & $-22,417(-50.6 \%)$ \\
\hline Total & $\mathbf{1 0 1 , 0 9 8}$ & $\mathbf{5 2 , 4 4 9}$ & $\mathbf{- 4 8 , 6 4 9}(-\mathbf{4 8 . 1} \%)$ \\
\hline
\end{tabular}

Fuente: Iniciativa de Gestión de Información de Movilidad Humana en el Triángulo Norte (NTMI). https://clck.ru/NXZ7n 
Hasta el 22 de abril, 746 deportados desde los EE. UU. fueron enviados a centros de contención dedicados exclusivamente para esa población. De acuerdo con el ministro de Salud, los deportados representan un grupo de riesgo debido a que vienen de un país donde circula activamente el virus (Cáceres y Lazo, 2020); así lo declaró el ministro en conferencia de prensa el 17 de abril. El escaso o nulo acceso a la estadística estatal sobre las cifras exactas de deportados recibidos por el país ha sido denunciada por el procurador para la Defensa de los Derechos Humanos (PDDH):

El procurador dijo a El Faro que ha pedido información oficial del número de retornados y sus condiciones de salud, pero que hasta la fecha el Gobierno no les ha respondido. La procuradora adjunta de la PDDH encargada de ver la situación de las personas retornadas no tiene certeza si entre los retornados hay casos positivos de COVID-19, porque Migración no le ha dado la información completa: "Hasta el sábado (19 de abril), nos enviaron un listado de 500 personas (que fueron albergadas en San Salvador) que no tienen la enfermedad". Ella plantea que no puede confirmar la veracidad de este dato porque el Gobierno restringe la información y no explica el estado del resto de deportados, que a la fecha asciende a 1530 (Cáceres y Lazo, 2020).

Esto creó un desafío para dimensionar el problema y su abordaje: ¿̇si representan un grupo de riesgo, como manifestó el ministro de Salud, por qué no se envió a centros de contención a todos los casos?

Aparte de los problemas detectados con respecto a las cifras sobre deportados, se han reportado otros relacionados a la atención de las personas deportadas. El 11 de mayo, unas 25 personas se fugaron del centro de contención donde permanecían en cuarentena, al haber sido deportadas desde los EE. UU. en medio de la pandemia. Los protestantes, en declaraciones a la prensa local, dijeron que lo hicieron por temor a contagiarse del COVID-19 ante el hacinamiento que hay en esas instalaciones y porque llevaban más de 40 días de estar en observación.

No es la única vez que ha habido motines $e$ intentos de fuga en los centros de contención. La UMO de la PNC ha intervenido, al menos, en seis ocasiones en varios centros de contención.

El usuario de Twitter Daniel Pineda (@ daniel_pineda1) publicó el 17 de mayo en su perfil un video grabado por afectados recluidos en el centro de contención ubicado en el gimnasio Adolfo Pineda. En el video denunciaban la ausencia de condiciones de distanciamiento social, instalaciones en las que se filtraba la lluvia, entre otras malas condiciones. Exigían que se les dieran a conocer los resultados de las pruebas que les habían realizado y que se les liberara. La protesta surtió efecto y, posteriormente, fueron puestos en libertad.

Aparte de los problemas anteriormente mencionados, en los centros de contención se señalaron otras problemáticas, como el caso de las personas que estuvieron más de un mes retenidas sin ser notificadas sobre su estado de salud. Además, muchas de las personas en cuarentena en dichos centros fueron retenidas en las calles por la PNC o la Fuerza Armada, a pesar de que la Sala de lo Constitucional de la Corte Suprema de Justicia había advertido al Gobierno de que estas privaciones de libertad eran inconstitucionales.

Finalmente, gracias al apoyo legal, 33 personas que tenían más de un mes de estar detenidas en centros de contención presentaron una denuncia colectiva ante la CIDH, en la que se solicitaba que ordenara al Estado salvadoreño medidas cautelares encaminadas a solventar las vulneraciones a los derechos humanos. De acuerdo con reportes periodísticos, 11 de las 33 personas que interpusieron la demanda contaban ya con una resolución favorable por parte de la Sala de lo Constitucional en solicitudes de habeas corpus. En su momento, estas 11 personas 
aseguraron que se les habían realizado dos pruebas para detectar el COVID-19 sin que se les hubieran entregado los resultados. En estos casos, de acuerdo con el periódico El Faro, la Sala de lo Constitucional ordenó a las autoridades del Ministerio de Salud realizar de inmediato las pruebas del COVID-19 a las personas demandantes y liberarlas en el caso de que las mismas resultaran negativas. Al actualizar la información, vemos que desde marzo a junio el país recibió 2571 deportados desde los EE. UU. Y, a la fecha, no se sabe exactamente cuál es el protocolo de atención, si se les hacen pruebas del COVID-19, si van a centros de contención, o si van a cuarentena domiciliar, etc. No se sabe nada.

\section{El caso de los \#VaradosSV}

En México, se ha escuchado hablar de centroamericanos "varados" que, por cansancio, por la burocracia del sistema de asilo y/o por haber conseguido un empleo, se quedaban a vivir en las ciudades de tránsito migratorio. Sin embargo, en este apartado, al hablar de personas varadas, se hace referencia a los 4500 salvadoreños y salvadoreñas (dato de la PDDH) que no pudieron ingresar al país desde que el 17 de marzo se cerró el aeropuerto. Se reporta que hay ciudadanos salvadoreños varados en alrededor de 80 países del mundo, la gran mayoría en los EE. UU. En la red social Twitter, los usuarios varados crearon el hashtag \#VaradosSV y desde ahí continúan denunciando su problemática, ya que el Gobierno salvadoreño no ha podido repatriarlos tras casi cuatro meses desde el cierre del aeropuerto.

Algunos países como Costa Rica y Guatemala gestionaron vuelos humanitarios para que sus connacionales pudieran retornar a sus países. Las personas varadas denuncian que han tenido que incurrir en altos costos de alojamiento en hoteles y de manutención diaria. Además, entre los varados, hay personas que padecen de enfermedades crónicas y no han podido adquirir sus medicamentos. Otros dejaron en manos de familiares y amigos a hijos e hijas pequeños. Así, cinco o siete días de viaje se convirtieron en casi cuatro meses de ausencia de sus hogares con consecuencias incuantificables en términos económicos, de salud, laborales y familiares.

\subsection{Acciones legales para volver a casa}

Un abogado, ciudadano salvadoreño y uno de entre los muchos varados, tomó la iniciativa de interponer una demanda de amparo a la Sala de lo Constitucional, con el fin de que se le exigiera al Gobierno de El Salvador un plan de repatriación para los ciudadanos varados. La petición de amparo fue respaldada por 200 salvadoreños que la firmaron.

El 8 de abril, la Sala de lo Constitucional admitió la demanda de amparo y ordenó al Gobierno de El Salvador presentar un plan para la repatriación gradual de los salvadoreños que se encuentran en el exterior. Posteriormente, la Asamblea Legislativa aprobó un decreto ${ }^{2}$ que también obligaba al Gobierno a que autorizara el ingreso de los connacionales y definiera alternativas que permitieran su reingreso sin afectar la cuarentena por el COVID-19.

Finalmente, en abril 2020, el Gobierno presentó un plan de repatriación (disponible en https://clck.ru/NMgHp) que, de acuerdo con los afectados, no presenta una acción sustantiva que incluya plazos para retorno asistido, grupos priorizados ni nada que se parezca a lo que la Sala de lo Constitucional le ordenó.

Por su parte, el 10 de mayo, en conferencia de prensa, la canciller salvadoreña presentó el plan para repatriar a los salvadoreños y mencionó que el Ministerio de Relaciones Exteriores realizó un censo en el que se identificaron a 2890 connacionales varados en 80 países. Sin embargo,

2 Decreto Legislativo n. 621 del 1 de abril, vetado por Bukele el 21 de abril. Posteriormente, el 30 de abril, la Asamblea Legislativa superó con 60 votos el veto presidencial. 
de acuerdo con la PDDH, hay alrededor de 4500 personas varadas. La canciller afirmó que la repatriación tomaría un tiempo estimado de 14 semanas y se daría prioridad a los 1200 casos que están en situación de mayor vulnerabilidad. Además, indicó que han identificado, al menos, a 558 personas que estaban infectadas del COVID-19; 354 de ellas estarían en los EE. UU. (Ministerio de Relaciones Exteriores, 2020). No obstante, representantes de las personas varadas han afirmado que este dato no es cierto. El plan de repatriación del Gobierno fue recibido con mucho pesimismo por los varados debido al largo tiempo que les tomaría su repatriación.

Debido a la poca voluntad mostrada por el Gobierno de El Salvador para agilizar el proceso de repatriación de las personas varadas, algunos de ellos han ingresado por fronteras terrestres y bajo sus propios medios. Ante esto, el secretario de la $\mathrm{CIDH}$ declaró que "el derecho más esencialmente violado en El Salvador es el derecho a la nacionalidad". Esta declaración fue realizada en conferencia virtual con la PDDH (Arévalo, 22 de mayo de 2020).

Ante esta situación, las personas varadas han optado por organizarse para visualizar su problemática en las redes sociales a través del hashtag \#VaradosSV. Además, han conseguido el apoyo jurídico de abogados por medio de los cuales han interpuesto el recurso de amparo ante la Corte Suprema de Justicia. Hasta el cierre de este informe, desde el 1 de mayo hasta este 3 de julio, han llegado al país 2170 personas, como parte del Plan de Repatriación aprobado por el presidente de la República, Nayib Bukele. Miles esperan regresar a casa todavía.

\section{Niñez migrante}

En el contexto de la pandemia del COVID19, la niñez migrante no ha estado a salvo de la deportación ni del contagio de la enfermedad. El interés superior de los niños, niñas y adolescentes y otras garantías tampoco les ha protegido durante esta crisis.

De acuerdo con datos de la Iniciativa de Gestión de Información de Movilidad Humana en el Triángulo Norte (NTMI, por sus siglas en inglés), de enero a mayo de 2019 , el total de niñez migrante deportada originaria de los países del Triángulo Norte centroamericano fue la siguiente:

Tabla 7. Niñez migrante deportada desde los EE. UU. y México a países del

Triángulo Norte en diciembre de 2019

\begin{tabular}{|l|c|c|c|c|}
\hline & Guatemala & Honduras & El Salvador & Total \\
\hline Niños & 3988 & 5652 & 1057 & $\mathbf{1 0 , 6 9 7}$ \\
\hline Niñas & 2380 & 3736 & 782 & $\mathbf{6 8 9 8}$ \\
\hline Total & 6368 & 9388 & 1839 & $\mathbf{1 7 , 5 9 5}$ \\
\hline
\end{tabular}

Fuente: Elaboración propia con datos de la Iniciativa de Gestión de Información de Movilidad Humana en el Triángulo Norte (NTMI). https://mic.iom.int/webntmi/

Para el primer semestre del año 2020 y en medio de la crisis generada por la pandemia de COVID-19, los datos demuestran que los
EE. UU. y México han seguido deportando a niños, niñas y adolescentes: 
Tabla 8. Niñez migrante deportada desde los EE. UU. y México: enero-mayo de 2020

\begin{tabular}{|l|c|c|c|c|}
\hline & Guatemala & Honduras & El Salvador & Total \\
\hline Niños & 2346 & 1452 & 328 & $\mathbf{4 1 2 6}$ \\
\hline Niñas & 1223 & 852 & 237 & $\mathbf{2 3 1 2}$ \\
\hline Total & 3569 & 2304 & 565 & $\mathbf{6 4 3 8}$ \\
\hline
\end{tabular}

Fuente: elaboración propia con datos de la Iniciativa de Gestión de Información de Movilidad Humana en el Triángulo Norte (NTMI). https://mic.iom.int/webntmi/

Al comparar las cifras de niñez deportada al Triángulo Norte de enero a mayo de 2019, el NTMI reportó 17,595 (10,697 niños y 6898 niñas), una cifra mucho mayor en total respecto de enero a mayo de 2020 , como se aprecia en la Tabla 8. México y los EE. UU. han deportado a 6438 niños, niñas y adolescentes (NNA) a los países del Triángulo Norte, una baja en las deportaciones de NNA del $63.4 \%$. No obstante, 6438 NNA no es una cifra que se pueda minimizar y es de analizar qué ocurrió en la pandemia con ellos.

De los NNA deportados, 565 eran salvadoreños; no obstante, la información publicada por el Consejo Nacional de la Niñez y de la Adolescencia de El Salvador (CONNA) sobre las personas atendidas en centros de contención especializados genera dudas y discrepa de los reportes de NNA deportados:

Tabla 9. Personas migrantes atendidas en centros de contención especializados

\begin{tabular}{|c|l|l|l|l|}
\hline \multicolumn{5}{|c|}{ Personas atendidas en centros de contención especializados } \\
\hline & Nigrantes & $\begin{array}{l}\text { NNA migrante } \\
\text { retornada no } \\
\text { acompañada }\end{array}$ & $\begin{array}{l}\text { Adultos que forman } \\
\text { parte del grupo } \\
\text { familiar de NNA }\end{array}$ & $\begin{array}{l}\text { Centros de } \\
\text { contención } \\
\text { especializados }\end{array}$ \\
\hline $\mathbf{5 5 2}$ & $\mathbf{3 2 9}$ & $\mathbf{8 6}$ & $\mathbf{4 8 9}$ & $\mathbf{2 1}$ \\
\hline
\end{tabular}

Fuente: elaboración propia a partir de datos de la cuenta oficial de Twitter del CONNA. https://twitter. com/CONNA_ES/status/1283551925150130178/photo/1

El dato afirma que únicamente atendió a 329 NNA retornados. ¿Qué ocurrió con el resto de NNA retornados? La directora de Operaciones de Programas en Save the Children y especialista en niñez migrante afirma que los derechos de la niñez no se pierden durante la movilidad, independientemente de la condición migratoria de los NNA. Pese a ello, lo que se ha evidenciado en esta crisis es lo contrario: la niñez es vulnerada en sus derechos fundamentales al sufrir desplazamiento interno forzado durante el tránsito. En los países de destino, sufren detención y son separados de sus familias (Chávez, 2020). Luego, al ser deportados, se les niega el derecho a la protección y el interés superior del menor es subordinado al interés del Estado que lo deporta.
Varios especialistas en temas de niñez entrevistados para este informe y que solicitaron anonimato, coincidieron en que, desde junio de 2019, con la llegada de Nayib Bukele al Gobierno salvadoreño, todo el sistema de protección integral de niñez fue desactivado. Al llegar la crisis por la pandemia del COVID19, no había coordinación ni protocolo activo porque el Sistema Nacional de Protección de la Niñez y de la Adolescencia, creado en 2009 a partir de la aprobación de la Ley de Protección Integral de la Niñez y Adolescencia (LEPINA), se encontraba desmantelado o desmovilizado.

Por ello, cuando la niñez migrante llega deportada a El Salvador es recibida por personal de cancillería, personal de la 
Dirección General de Migración y Extranjería y no por instituciones del Sistema Nacional de Protección de la Niñez y de la Adolescencia. En consecuencia, niños, niñas y adolescentes, incluso las familias que han sido deportadas, están siendo enviadas a espacios de hoteles y otros centros de cuarentena y es ahí donde el sistema no ha dado ninguna respuesta apegada a derecho, asegurando que no haya separación familiar, garantizando la protección de la niñez. La Alianza para la Protección de la Niñez y Adolescencia en la Acción Humanitaria (2019) menciona que "las mismas medidas emprendidas para prevenir y controlar la transmisión del COVID-19 pueden conllevar riesgos de protección en niños, niñas y adolescentes. Las medidas de cuarentena y aislamiento en el hogar, las instalaciones o zonas concretas pueden afectar negativamente a los niños, las niñas y sus familias". En consonancia con esa advertencia, es importante el pronunciamiento de un colectivo de organizaciones protectoras de niñez migrante en el que denuncian que:

La pandemia de COVID-19 ha profundizado la situación de vulnerabilidad de la niñez, adolescencia y sus familias. Los Estados no han considerado las características particulares de este grupo al momento de tomar medidas para evitar la propagación del COVID-19. Existe un gran número de niños, niñas y adolescentes que regresa a sus países de origen y este retorno los posiciona en peores condiciones: violencia de grupos criminales y mayor precariedad y pobreza (Al Otro Lado et al., 15 de abril de 2020).

\section{Conclusiones}

Entre 2017 y 2020, la administración del presidente Trump ha aplicado unas políticas de inmigración que han causado un daño enorme a miles de personas, que han despreciado $\mathrm{y}$ violado de manera flagrante tanto la legislación estadounidense como el derecho internacional y que parecen haber tenido por objeto desmantelar por completo el sistema de asilo de los EE. UU. Entre estas políticas y prácticas figuran: 1) expulsiones ilegales masivas de solicitantes de asilo en la frontera entre los EE. UU. y México (fast track); 2) separaciones ilegales de familias, con las que la administración Trump ha infligido deliberadamente sufrimiento extremo a ellas, en forma de malos tratos que han llegado al grado de tortura en algunos casos muy similares a las ocurridas en los campos de concentración, y 3) detenciones cada vez más arbitrarias e indefinidas de solicitantes de asilo, sin posibilidad de libertad condicional. Todas estas prácticas han continuado a pesar del inminente riesgo de contagio del COVID19 , lo que constituye tratos o penas crueles, inhumanos o degradantes, terminantemente prohibidos por el derecho internacional. Los EE. UU. han aprovechado el COVID-19 para obstaculizar aún más el acceso al asilo.

El COVID-19 ha parado los trámites para solicitar asilo, pero no las deportaciones, sin importar las dificultades que haya significado para cada país a causa de la pandemia del COVID-19. Ni el ICE, ni el INM, ni las Direcciones de Migración y Extranjería del Triángulo Norte están en cuarentena. La maquinaria de deportación sigue en marcha imparable.

El Gobierno mexicano, ante la pandemia, optó por deportar a los migrantes del Triángulo Norte de Centroamérica que estaban detenidos en las estaciones migratorias. Así les negó el acceso a la protección internacional, violando la validez de los principios y las normas de la Convención sobre el Estatuto de los Refugiados de 1951 y su Protocolo de 1967, los instrumentos regionales sobre refugiados aplicables al principio de no devolución.

En El Salvador, la gestión de los deportados, la niñez migrante y los varados en el contexto de la emergencia debe enmarcarse como parte de la respuesta del Gobierno salvadoreño a la pandemia del COVID-19, caracterizada por la ausencia del enfoque de derechos humanos. Al analizar la respuesta gubernamental a la pandemia, esta ha sido, desde el principio, improvisada (nunca ha habido un plan nacional, ni lo hay aún); 
errada (el concepto de salud no incluye bienestar del país y crea crisis de hambre simbolizada con el fenómeno de las banderas blancas que la gente ha colgado en sus domicilios); sin transparencia (no se han rendido cuentas de la gestión financiera en lo que va de la emergencia; no se acepta la contraloría social). En términos políticos, el Gobierno pretende hacer quedar mal ante el pueblo a los partidos de oposición en la Asamblea Legislativa (en la práctica, estaría ya en campaña electoral de cara a las elecciones del 28 de febrero de 2021) y lo más grave:

Desde la pandemia, afirmando la necesidad de actuar rápida y decisivamente para frenar al virus, Bukele ha arremetido con acciones que le otorgan más poder y ponen en riesgo a los ciudadanos. Con maniobras que recuerdan los días oscuros de la guerra civil salvadoreña, ha autorizado a las fuerzas de seguridad el uso de la fuerza letal contra presuntos pandilleros, y les ha ordenado detener y confinar a cualquiera que viole la cuarentena obligatoria. Como resultado, cientos de personas han sido ilegalmente detenidas en "centros de contención" hacinados que podrían convertirse en vectores para la propagación de la enfermedad. A pesar de que la Sala de lo Constitucional de El Salvador ha resuelto en repetidas ocasiones la inconstitucionalidad de sus órdenes de detener individuos que violen la cuarentena, Bukele ha desafiado estas resoluciones abiertamente, instalando una crisis constitucional en el país (Thale, 7 de mayo de 2020).

En una carta abierta dirigida a Nayib Bukele enviada por seis organizaciones internacionales, le advierten que es:

alarmante que las detenciones por violaciones de la cuarentena, incluso las detenciones prolongadas en "centros de contención", sigan a pesar de las decisiones judiciales mencionadas. Debemos recordar que, como han enfatizado la Alta Comisionada para los Derechos Humanos de las Naciones Unidas y la Comisión Interamericana de Derechos Humanos, aunque un estado de emergencia implica ciertas restricciones de derechos, toda medida gubernamental, incluyendo órdenes de cuarentena y su aplicación, deben ser necesarias, proporcionadas y llevadas a cabo dentro de un marco de respeto a las normas internacionales de derechos humanos (Amnistía Internacional et al., 30 de abril de 2020).

No hay duda de que la gestión de la pandemia por parte de Bukele ha rebasado la frontera salvadoreña y su conducta autoritaria y antidemocrática está en la mirada de las instituciones nacionales e internacionales que velan por los derechos humanos. No fue extraño que, hasta el presidente de la Comisión de Asuntos Exteriores del Congreso de los EE. UU., Eliot Engel, envió una carta al mandatario salvadoreño en la que expone su "preocupación" ante las acciones recientes del Ejecutivo, las cuales ponen "en riesgo" la democracia del país. En la carta, el Comité de Asuntos Internacionales de la Cámara Baja pide "reconsiderar" las acciones recientes del Gobierno, como las retenciones de salvadoreños que rompen la cuarentena domiciliar ante la emergencia sanitaria por el coronavirus (COVID-19), así como el desacato a las sentencias de la Sala de lo Constitucional. Esto "socava la constitución salvadoreña y las normas internacionales", por lo que piden que Bukele no use como "pretexto" el coronavirus para llevar a cabo dichas medidas. También el Congreso expresa al Gobierno su "preocupación por varias acciones recientes que se han tomado las cuales ponen en peligro los derechos humanos de la población salvadoreña y la democracia del país" (Engel \& Sires, 29 de abril de 2020). 


\section{Recomendaciones al Gobierno salvadoreño}

\section{Frente a los deportados}

Establecer negociaciones de alto nivel con autoridades de México y los EE. UU. para frenar las deportaciones hasta que se logre contener el COVID-19.

Dado que los deportados ya estuvieron en centros de detención en los EE. UU. o en estaciones migratorias en México, el Estado salvadoreño no puede seguir revictimizándolos, enviándolos a centros de contención en El Salvador. Lo correcto es que el Gobierno les realice la prueba del COVID-19 y, si no están contagiados, deben ser enviados a sus domicilios.

Debe dar atención y protección a salvadoreños deportados y retornados, en particular a aquellos que han sufrido desplazamiento forzado antes de migrar.

Se debe garantizar la inclusión laboral, educativa y cultural para personas retornadas y sus familias. Al haber estado fuera del país, estas personas no fueron incluidas entre los beneficiarios de subsidios económicos por la pandemia y deberían ser incluidos inmediatamente, así como en otros programas de reactivación socioeconómica.

Debido al COVID-19, los deportados han sido estigmatizados como potenciales portadores del coronavirus. Ante esta realidad, es necesario impulsar de inmediato una campaña de sensibilización y combate del estigma en la sociedad y las familias.

Asimismo, el Gobierno debe abordar y disminuir las causas estructurales que propician la migración irregular a través de políticas económicas, de seguridad y políticas sociales integrales, todo ello en el marco de respeto de los derechos humanos.

El Gobierno debiera considerar la propuesta de política pública de migración y retorno diseñada por el asocio académico conformado por la Fundación Dr. Guillermo
Manuel Ungo (FUNDAUNGO), la Universidad Centroamericana "José Simeón Cañas" (UCA), la Universidad Don Bosco (UDB) y la Facultad Latinoamericana de Ciencias Sociales (FLACSO). Es un aporte actualizado, técnico y hecho desde una mirada integral al problema de la migración salvadoreña, que puede consultarse aquí: https://www. fundaungo.org.sv/migracion-y-retorno-2).

\section{Frente a los salvadoreños varados}

El Gobierno salvadoreño está violando los derechos humanos (salud, nacionalidad o residencia, integridad personal) de los salvadoreños que quieren regresar a su país y no pueden. Por lo tanto:

Debe agilizar con carácter urgente el retorno asistido de todos los compatriotas, tal como ordenó la resolución de la Sala de lo Constitucional, priorizando los casos críticos y haciendo todas las coordinaciones necesarias dentro y fuera del país, para que ellos vuelvan a sus familias.

Debe parar la estigmatización de los varados y, por el contrario, diseñar y ejecutar una campaña de sensibilización para su no discriminación.

Debe contactar y coordinar mecanismos para apoyar a los varados en cuanto a proveer alimentación, acceso a medicamentos, ayuda en pago de alojamiento en los países donde ellos están contra su voluntad y debido a la negligencia del Gobierno.

\section{Frente a los NNA}

El Gobierno debe fortalecer la capacidad operativa, técnica y financiera del Sistema de Protección Integral de Niñas, Niños y Adolescentes, del cual forma parte fundamental el Consejo Nacional de la Niñez y de la Adolescencia (CONNA) y el Instituto Salvadoreño para el Desarrollo Integral de la Niñez y Adolescencia (ISNA). Este sistema de protección debe estar activado totalmente y recibir y supervisar las medidas de protección especial para la niñez y la adolescencia migrantes, desplazados y refugiados ante la 
COVID-19, basadas en los enfoques de derechos, de género y sistémico.

El Gobierno debería velar junto a los Gobiernos de México y de los EE. UU. acuerdos bilaterales y multilaterales enfocados a la protección transfronteriza de los derechos de niñas, niños y adolescentes en contextos de movilidad humana, para garantizar la protección, la salud, la alimentación, la educación y los medios de vida durante cualquier etapa del ciclo migratorio, asegurando que las medidas de protección iniciadas por un Estado tengan continuidad en los otros.

\section{Recomendación general}

El Gobierno debe apegarse al Estado de derecho y las reglas democráticas: debe acatar las resoluciones de la Sala de lo Constitucional de la Corte Suprema de Justicia y el respeto a su mandato, así como colaborar con la Asamblea Legislativa, promover una gestión transparente, abierta al diálogo y la búsqueda de consensos políticos, económicos y sociales, en coordinación con y respeto de la función de otras instancias estatales.

El Gobierno tiene que retirar el protagonismo que en la pandemia han tenido fuerzas policiales y militares.

La conducción de la crisis del COVID-19 corresponde a las autoridades de salud, con el apoyo de un comité técnico integrado por especialistas en la materia.

El Gobierno debe definir protocolos de actuación para cada una de las instituciones que están realizando funciones de contención del COVID-19. Estas tienen que fundamentarse en parámetros legales y normativa internacional en materia de derechos humanos.

\section{Referencias bibliográficas}

Al Otro Lado, Alianza Americas, Asylum Access Mexico (AAMX) A. C., Bloque Latinoamericano sobre Migración, Centro de Derechos Humanos Fray Matías de Córdova, Coalición Internacional contra la Detención (IDC), Denver Justice and Peace
Committee, Fundación para la Justicia y el Estado Democrático de Derecho, Grupo de Monitoreo Independiente de El Salvador (GMIES), Human Rights First, Instituto para las Mujeres en la Migración (IMUMI), Latin America Working Group (LAWG), Mesa Nacional para las Migraciones y Refugiados en RD, Network in Solidarity with the People of Guatemala (NISGUA), Nicaragua Center for Community Action, Oficina en Washington para Asuntos Latinoamericanos (WOLA), Oxfam México, Sin Fronteras IAP, Sisters of Mercy of the Americas-Justice Team, Testigos en la Frontera (Witnesses at the Border), Women's Refugee Commission. (15 de abril de 2020). Carta al gobierno de México: es imperativo proteger los derechos de personas migrantes durante la pandemia COVID-19. WOLA. https://www.wola.org/es/2020/04/ carta-gobierno-mexico-derechos-humanos-migrantes-pandemia-COVID-19/

Alianza para la Protección de la Niñez y Adolescencia en la Acción Humanitaria. (2019). Nota técnica: Protección de la niñez y adolescencia durante la pandemia del coronavirus. UNICEF. https://www.unicef.org/ media/66276/file/SPANISH_Technical\%20 Note:\%20Protection\%20 of $\% \overline{2}$ CChildren $\% 20$ during\%20the\%20COVID-19\%20Pandemic. pdf

Alto Comisionado de las Naciones Unidas para los Refugiados (ACNUR). (16 de marzo de 2020). Consideraciones jurídicas sobre el acceso al territorio para las personas en necesidad de protección internacional en el contexto de la respuesta frente al COVID-19. Refworld. https://www.refworld.org.es/doci$\mathrm{d} / 5 e 74 e 29 \mathrm{a} 4 . \mathrm{html}$

Alvarado, J. (26 de septiembre de 2019). Honduras pone el último ladrillo en el muro centroamericano de Trump. El Faro. https:// elfaro.net/es/201909/centroamerica/23675/ Honduras-pone-el-\%C3\%BAltimo-ladrillo-enel-muro-centroamericano-de-Trump.htm

American Civil Liberties Union (ACLU). (30 de abril de 2020). New Report Shines Spotlight on Abuses and Growth in Immigrant 
Detention under Trump. https://www.aclu.org/ press-releases/new-report-shines-spotlightabuses-and-growth-immigrant-detention-under-trump

Amnistía Internacional (AI), Centro por la Justicia y el Derecho Internacional (CEJIL), Fundación para el Debido Proceso (DPLF), Iniciativa Mesoamericana de Mujeres Defensoras de Derechos Humanos (IMD), Oficina en Washington para Asuntos Latinoamericanos (WOLA) y Organización Mundial Contra la Tortura (OMCT). (30 de abril de 2020). Carta abierta a Nayib Bukele, Presidente de El Salvador, de parte de Organizaciones Internacionales. Amnistía Internacional. https:// www.amnesty.org/download/Documents/ AMR2922342020SPANISH.pdf

Arévalo, M. (22 de mayo de 2020). GOES viola derechos de los varados: CIDH. La Prensa Gráfica. https://www.laprensagrafica. com/elsalvador/GOES-viola-derechos-de-losvarados-CIDH-20200521-0067.html

Artiga-González, A. (24 de febrero de 2020). Cátedra de Realidad Nacional Personal UCA [Ponencia]. Universidad Centroamericana "José Simeón Cañas".

Asociación Azul Originario, Colegio Médico de El Salvador (COLMED), CRISTOSAL, Equipo Impulsor Nacional del Acuerdo de Escazú-El Salvador, Fundación de Estudios para la Aplicación del Derecho (FESPAD), Instituto Centroamericano de Estudios Fiscales (ICEFI), Instituto de Derechos Humanos de la UCA (IDHUCA) y Servicio Social Pasionista (SSPAS). (5 de mayo de 2020). Todavía es tiempo para corregir el camino [Comunicado]. https://www.fespad.org.sv/comunicado-todavia-es-tiempo-para-corregir-el-camino-y-avanzar/\#more-16500

Cáceres, G. y Lazo, R. (23 de abril de 2020). El Salvador defiende a EE. UU. y niega que estén llegando deportados con COVID-19. El Faro. https://elfaro.net/ es/202004/el salvador/24320/El-Salvadordefiende-a-Estados-Unidos-y-niega-que-esténllegando-deportados-con-COVID-19.htm
Chacón, Ó. (7 de mayo de 2020). Impacto del COVID-19 en política de asilo en EE. UU. [Entrevista].

Chávez, L. (13 de mayo de 2020). Derechos de la NNA migrante [Entrevista].

Comisión Española de Ayuda al Refugiado (CEAR). (2018). México: Destino forzoso para personas refugiadas. https://www.cear. es/wp-content/uploads/2018/05/INFORME_ MEXICO.pdf

Comisión Mexicana de Ayuda a Refugiados (COMAR). (2 de agosto de 2020). Estadísticas al mes de julio 2020 [Blog]. https://www.gob.mx/comar/articulos/ julio-2020?idiom $=$ es

Coordinadora Institucional de Promoción por los Derechos de la Niñez (CIPRODENI), Coordinadora de Instituciones Privadas pro las Niñas, Niños, Adolescentes, Jóvenes y sus Derechos (COIPRODEN), Save the Children-México, Red para la Infancia y la Adolescencia (RIA) y Red por los Derechos Humanos de los Niños, Niñas y Adolescentes (REDHNNA). (5 de mayo de 2020). Llamado al Comité de los Derechos del Niño y a la Comisión Interamericana de los Derechos Humanos para Promover en los Estados la Protección y Defensa de los Derechos Humanos de la Niñez y Adolescencia Migrante y sus Familias en el Contexto del COVID-19 en la Región Americana. Voz de la Diáspora. https:/vozdeladiasporanews.com/wp-content/uploads/2020/05/PronunciamientoProteccio\% CC\%81n-Nin \% CC\%83ezMigrante-COVID-19-Soiciedad-CIVIL-1-1.pdf

Dalby, C. y Carranza, C. (22 de enero de 2019). Balance de InSight Crime sobre los homicidios en 2018. InSight Crime. https:// es.insightcrime.org/noticias/analisis/balancede-insight-crime-sobre-los-homicidios-en-2018/

Damián, F. (12 de mayo de 2020). Migración evitó contagios de coronavirus repatriando a más de 4 mil extranjeros. Milenio.com. https://www.milenio.com/politica/ coronavirus-4-mil-303-migrantes-repatriados-inm 
Departamento de Sociología y Ciencias Políticas de la UCA. (24 de octubre de 2019). Análisis sobre los 100 días de gobierno: ¿continuidades o cambios? Noticias UCA. https://noticias.uca.edu.sv/audios/analisis-sobre-los-100-dias-de-gobierno-continuidades-o-cambios

EFE. (2 de noviembre de 2018). Ocho datos básicos sobre las caravanas de migrantes en México. Elsalvador.com. https:// www.elsalvador.com/noticias/internacional/ datos-basicos-sobre-las-caravanas-de-migrantes-en-mexico/535264/2018/

Engel, E. \& Sires, A. (29 de abril de 2020). Engel \& Sires Urge Salvadoran President to Respect Democratic Norms. https://clck.ru/ NYppF

Gómez, M. (2020). Caravanas desde El Salvador. En Eguren, J. y Hernández Bonilla, S. (Eds.). Caravanas de migrantes: manifestaciones de la compleja realidad centroamericana (pp. 38-42). Servicio de Publicaciones de la Universidad Pontificia Comillas.

Guevara, T. (3 de mayo de 2020). Autoritarismo de Bukele pone en máxima alerta a los observadores internacionales. Elsalvador.com. https://www.elsalvador.com/ eldiariodehoy/autoritarismo-bukele-maxima-alerta-observadores-internacionales/711245/2020/

Instituto Nacional de Migración (INM). (26 de abril de 2020). Actúa INM con responsabilidad ante la contingencia por COVID-19. Boletín N. ${ }^{\circ}$ 125/2020. https:/www.gob.mx/ inm/prensa/actua-inm-con-responsabilidad-ante-la-contingencia-por-COVID-19-241034

Instituto Universitario de Opinión Pública (IUDOP). (18 de septiembre de 2019). Encuesta de evaluación de los primeros 100 días de Gobierno de Nayib Bukele. http:// www.uca.edu.sv/iudop/wp-content/uploads/ PPT-100NB-V7-18-09-2019-7am.pdf

La 72. Hogar-Refugio para Personas Migrantes. (1 de abril de 2020). Carta a las autoridades del Estado mexicano, a los medios de comunicación, a la sociedad civil nacional e internacional. https:/la72.org/wp-content/uploads/2020/04/ Comunicado-010420.pdf

Lissardy, G. (27 de junio de 2019). Por qué están llamando "campos de concentración" a los lugares de detención de inmigrantes en EE. UU. BBC News Mundo. https:/www.bbc.com/mundo/ noticias-internacional-48781955

Martínez, C. (19 de mayo de 2020). Presentan denuncia colectiva ante $\mathrm{CIDH}$ por detenciones durante la cuarentena. El Faro. https://elfaro.net/es/202005/el_salvador/24441/ Presentan-denuncia-colectiva-ante-CIDH-pordetenciones-durante-la-cuarentena.htm

Massey, D. y Pren, K. (2013). La guerra de los EE. UU. contra la inmigración. Efectos paradójicos. Documents d'Anàlisi Geogràfica, 59(2), 209-237. https:/www.ncbi.nlm.nih.gov/ pmc/articles/PMC4827256/

Menchú, S. y Mariscal, Á. (18 de mayo de 2020). "iLos llevan o los quemamos!": el dramático retorno de los migrantes a sus comunidades. Revista GatoEncerrado. https:// gatoencerrado.news/2020/05/18/el-dramatico-retorno-de-los-migrantes-a-sus-comunidades/

Ministerio de Relaciones Exteriores. (10 de mayo de 2020). Gobierno anuncia avances en plan de repatriación de salvadoreños en el exterior y llegada de primer vuelo desde Panamá [Noticia]. https://rree.gob.sv/gobierno-anuncia-avances-en-plan-de-repatriacion-de-salvadorenos-en-el-exterior-y-llegada-de-primer-vuelo-desde-panama/

Ministerio de Relaciones Exteriores. (7 de mayo de 2020). Gobierno de El Salvador informa sobre el fallecimiento de connacional en un centro de detención del ICE por COVID-19 [Noticia]. https:// rree.gob.sv/aviso/gobierno-de-el-salvadorinforma-sobre-el-fallecimiento-de-connacionalen-un-centro-de-detencion-del-ice-por -COVID-19/?fbclid=IwAR2hya1yrw6cCxmtl aD0NFo713uL1WV8TxuHZaF1Xuov8EseeA 9kqDE_nJE 
Ministerio de Relaciones Exteriores. (2017). Política Nacional para la Protección y Desarrollo de la Persona Migrante Salvadoreña y su Familia. https://rree. gob.sv/wp-content/uploads/2018/04/ Poli\%CC\%81tica-Nacional-para-laProteccio\%CC\%81n-y-Desarrollo-de-laPersona-Migrante-Salvadoren\%CC\%83a-ysu-Familia.pdf

Ministerio de Salud. (22 de enero de 2020). El Salvador toma medidas por alerta preventiva de la OMS ante nuevo Coronavirus. http://www.salud.gob.sv/22-012020-el-salvador-toma-medidas-por-alertapreventiva-de-la-oms-ante-nuevo-coronavirus/

Noe-Bustamante, L., Flores, A. \& Shah, S. (16 de septiembre de 2019). Facts on Hispanics of Salvadoran origin in the United States, 2017. Pew Research Center. https:// www.pewresearch.org/hispanic/fact-sheet/u-shispanics-facts-on-salvadoran-origin-latinos/

O'Connor, A., Batalova, J. y Bolter, J. (15 de agosto de 2019). Inmigrantes centroamericanos en los EE. UU. Migration Policy Institute. https://www.migrationpolicy.org/ article/inmigrantes-centroamericanos-en-los-estados-unidos

Organización Mundial de la Salud (OMS). (11 de marzo de 2020). Alocución de apertura del Director General de la OMS en la rueda de prensa sobre la COVID-19 celebrada el 11 de marzo de 2020. https://www.who.int/es/dg/ speeches/detail/who-director-general-s-opening-remarks-at-the-media-briefing-on-COVID19-11-march-2020

Pradilla, A. (12 de abril de 2020). Migrantes frente al COVID-19: entregados por EU, abandonados en México y con fronteras cerradas. Animal Político. https:/www. animalpolitico.com/2020/04/migrantes-frente-COVID-19-abandonados-mexico-fronteras-cerradas/

Programa de Asuntos Migratorios (PRAMI). (6 de mayo de 2020). Situación de las esta- ciones migratorias y solicitantes de asilo en México.

Rauda Zablah, N. (20 de septiembre de 2019). El Gobierno emula a Guatemala y acepta recibir a los asilados que Trump no quiere. El Faro. https://elfaro.net/es/201909/ el_salvador/23664/El-Gobierno-emula-aGüatemala-y-acepta-recibir-a-los-asilados-queTrump-no-quiere.htm

Redacción BBC News Mundo. (2 de noviembre de 2016). Cómo son los muros que ya existen en la frontera entre México y EE. UU. (y que Donald Trump va a ampliar). BBC News Mundo. https://www.bbc.com/ mundo/noticias-internacional-54090299

Sacchetti, M. (22 de julio de 2019). Trump administration to expand its power to deport undocumented immigrants. The Washington Post. https://www.washingtonpost. com/immigration/trump-administration-to-expand-its-power-to-deport-undocumented-immigrants/2019/07/22/76d09bc4-ac8e-11e9-b c5c-e73b603e7f38_story.html

Thale, G. (7 de mayo de 2020). La nueva generación de autoritarios latinoamericanos. El Faro. https://clck.ru/NYDLx

TRAC Immigration. (2020). Details on MPP (Remain in Mexico) Deportation Proceedings by Hearing Location and Attendance, Representation, Nationality, Month and Year of NTA, Outcome, and Current Status. https://trac.syr.edu/phptools/ immigration $/ \mathrm{mpp} /$

U.S. Immigration and Customs Enforcement. (9 de agosto de 2020). Guía de ICE sobre el COVID-19. https://www.ice.gov/ es/coronavirus

Williams, J. (19 de mayo de 2020). Actualización de Contexto EU y Frontera EU/ MX. Nogales, Arizona, EE. UU. [Correo electrónico interno]. 